\title{
Evaluation of CD4 count in patients receiving ART treatment in a tertiary rural hospital of India
}

\author{
Renge PS ${ }^{1}$, Narwane Sandeep Prakash ${ }^{2 *}$ \\ ${ }^{1}$ Student, ${ }^{2}$ Associate Professor, ${ }^{2}$ Dept. of Pharmacology, Rural Medical College, Loni, Maharashtra, India \\ *Corresponding Author: Narwane Sandeep Prakash \\ Email: drsandeepnarwane1984@gmail.com
}

\begin{abstract}
Introduction: The present study was aimed to evaluate the efficacy of new ART treatment as per the recent guidelines in treatment of AIDS patients by NACO on patients' CD4 count after 6 months of treatment.

Materials and Methods: The present study was Descriptive longitudinal type conducted in ART centre of Pravara Rural Hospital, Loni. The demography, Co-morbidities, ART treatment and CD4 count before and after first 6 months of therapy were recorded.

Results: In the present study, records of 100 patients were collected. Out of the 100 patients 38 were males, females were 62 and 1 transgender patient. Ninety one out of 100 patients were prescribed Tenofovir + Lamivudine + Efavirenz (TLE). There was a statistically significant increase in the CD4 count before $(416.7 \pm 322)$ and after ART treatment at an interval of 6 months $(520.89 \pm 317)$.

Conclusion: The initiation of ART in patients irrespective of CD4 count has been an improvement in the treatment therapy of HIV infected patients.
\end{abstract}

Keywords: ART, AIDS, HIV infection, CD4 count.

\section{Introduction}

Human Immunodeficiency Virus (HIV) is an enveloped virus of Retrovirus group which converts its viral RNA into double stranded DNA inside the host cell and integrates itself with the host cell DNA. ${ }^{1}$ The HIV infection is not being managed with antiretroviral therapy (ART), which has significantly improved the mortality and morbidity among the HIV infected patients. ${ }^{2}$

The helper $\mathrm{T}$ cells, also known as CD4 cells have an imported role in the immune system. Its count depletes drastically in the HIV infected patients. The lowered immunity leads to increase in the incidence of opportunistic infections. The CD4 count is used as a marker for the immune status and also gives the prognosis of treatment. ${ }^{3}$

In 2015, WHO guidelines stated, ART be initiated in HIV positive people at any CD4 cell count. It reported that the early start of treatment has the potential to "significantly reduce the number of people acquiring HIV infection and dying from HIV-related causes and significantly impact global public health". ${ }^{4}$ In view of change in guidelines in treatment of AIDS patients by NACO, it is important to study its impact on the remission of patients. Being an important indicator of patients' prognosis, the present study is planned to evaluate the effect on CD4 count with ART treatment patients in ART center of Pravara Rural Hospital Loni.

\section{Materials and Methods}

The present study was Descriptive longitudinal type conducted in ART centre of Pravara Rural Hospital, Loni. This was a retrospective record based study initiated after the Ethics committee approval. Permission from the Authority in charge of the ART centre to access the records was taken. The data from records were collected for the duration of.

The complete records of newly diagnosed and treated patients visiting ART for the first six months during the period of January 2017 to December 2018 and aging more than 18 years were included for the study. Incomplete records and records of patients with carcinoma or on steroid therapy were excluded from the study. The demography, Co-morbidities, ART treatment and CD4 count before and after first 6 months of therapy were recorded.

Data were extracted from the routinely maintained ART patient register. Date of entry into the study and subsequent follow up date of visits were noted. Follow up data on the key variable CD4 cell count (cells/mm3) has been collected before the initiation of the art treatment and after 6 months thereafter on treatment. Other variables considered are age (in years), sex, weight. No personal identification details were available in the ART register except the registration identity number, which has not been recorded. Also no information regarding HIV/AIDS status of a patient at enrollment or subsequent transition to AIDS during the study period (in case of a HIV patient) was available.

\section{Results}

In the present study, records of 100 patients were collected. Ninety one out of 100 patients were prescribed Tenofovir + Lamivudine + Efavirenz (TLE) followed by four with Zidovudine + Lamivudine + Efavirenz (ZL+ efa). Therapy was maintained in the anti-retro viral regimen throughout the study period in all the patients.

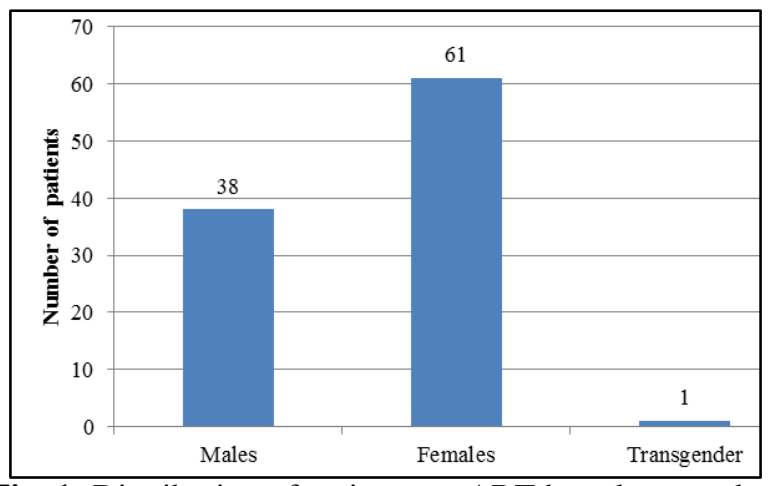

Fig. 1: Distribution of patients on ART based on gender. 
Out of the 100 patients 38 were males, females were 62 and 1 transgender patient (Figure no. 1).

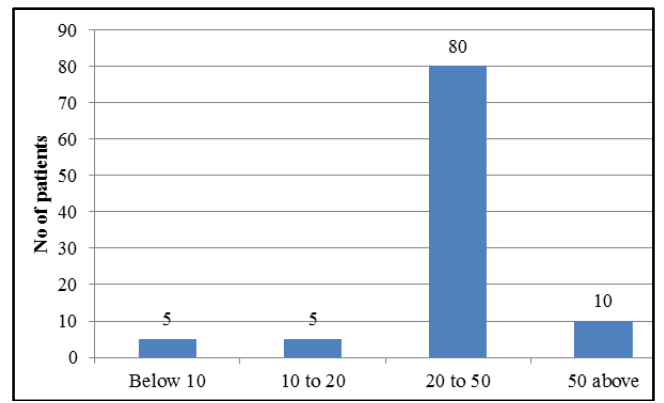

Fig. 2: Age distribution of patients on ART.

Figure 2 displays age distribution of the patients. Most of the patients belonged to the age group of $20-50$ years (80).

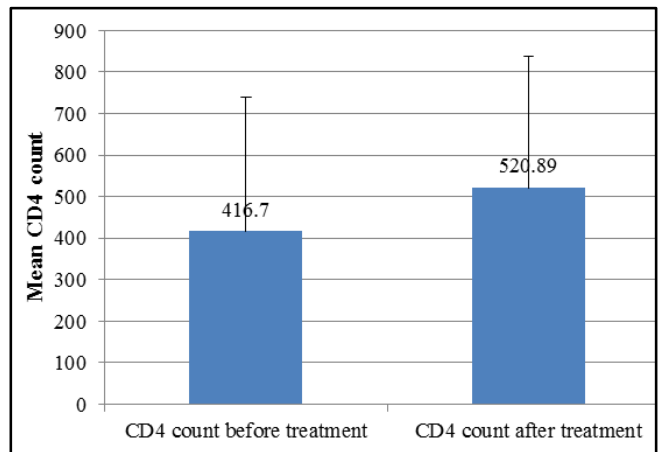

Fig. 3: CD4 count of patients before and after ART

Table 1: CD4 count (in cc/mm3) of patients before and after ART.

\begin{tabular}{|c|c|c|}
\hline & $\begin{array}{c}\text { CD4 count } \\
\text { before treatment }\end{array}$ & $\begin{array}{c}\text { CD4 count after } \\
\text { treatment }\end{array}$ \\
\hline Mean & 416.7 & $520.89^{*}$ \\
\hline SD & 322.059 & 317.1945 \\
\hline
\end{tabular}

*P=0.011, Paired t test.

Figure 3 shows the mean and SD of the CD4 count before $(416.7 \pm 520.89)$ and after ART treatment at an interval of 6 months $(322 \pm 317)$. There was statistically significant increase in the CD4 count after initiation of treatment $(\mathrm{P}=0.011$, Paired $t$ test $)$.

Table 2: Distribution of patients according to the CD4 count (in cc/mm3) range before and after ART.

\begin{tabular}{|c|c|c|}
\hline & Before ART & After ART \\
\hline$<100$ & 9 & 2 \\
\hline $101-200$ & 16 & 5 \\
\hline $201-300$ & 14 & 20 \\
\hline $301-400$ & 21 & 15 \\
\hline $401-500$ & 10 & 15 \\
\hline $500-1000$ & 25 & 36 \\
\hline$>1000$ & 5 & 7 \\
\hline
\end{tabular}

$\mathrm{P}=0.0161$, Chi-Squared test for independence

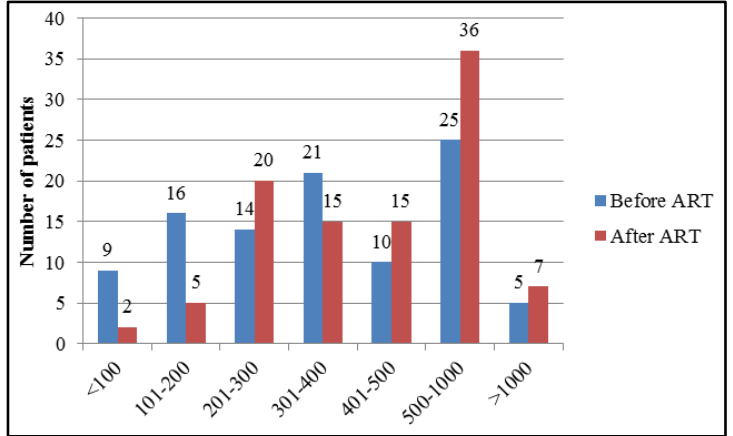

Fig. 4: Distribution of patients according to the CD4 count range before and after ART.

Fig. 4 and Table no. 2 shows the distribution of patients $\mathrm{CD}_{4}$ count before and after treatment of ART. There was a statistically significant difference in the number of patients belonging to $\mathrm{CD} 4$ range groups before and after ART $(\mathrm{P}=0.0161$, Chi-Squared test for independence). Most of the patients whose initial CD4 count was below 100 and between 101-200, later their CD4 count increased and the graph of patients in this range decreased. The number of patients in the group of 501-1000 showed marked increase in number of people.

\section{Discussion}

Since September 2015, the World Health Organization has recommended antiretroviral therapy (ART) for all persons with human immunodeficiency virus (HIV) infection, regardless of clinical stage or CD4 count ${ }^{5}$. ART program's facilitated ART initiation among persons with HIV infection enrolled in pre-ART care immediately after adoption of the Treat All policy. ${ }^{6}$

In our study the CD4 count raised from 416.7 to 520.89 , which was statistically significant. Bachani D, Kumarasamy N, Pujari S, Sharma A, Mrudula ND and Grover G, in their studies reported a gain in CD4 cell counts after initiation of ART. ${ }^{7-12}$ Grover $\mathrm{G}$ etal ${ }^{12}$ suggested significant increase in CD4 count at all stages of HIV/AIDS infection. Our observations support the findings of their studies.

As shown in Table 2, there was a statistically significant difference in the number of patients belonging to CD4 range groups before and after ART $(\mathrm{P}=0.0161$, ChiSquared test for independence). Thus, the overall increase in CD4 count is also reflected in the change of number of CD4 count range group, indicating an increase in the immunological status of the patients. After initiation of ART in patients, it was observed that there was overall improvement in their CD4 counts. This indicates necessity of treatment of all patients with ART irrespective of CD4 count.

However, there was decrease in the CD4 count of 26 patients, indicating decrease in their immunological status. This finding might suggest poor clinical status of the patients. However the clinical staging was not recorded in them and thus, cause of decrease in CD4 count in these patients cannot be ascertained. The overall findings suggest the efficacy of the ART regimen irrespective of its CD4 
count. Thus, the decrease in CD4 count of few patients emphasizes strongly the use of ART in all patients. Being a record based observational study on a smaller size, a study with prospective follow-up of the patients is required to confirm the finding of the study.

\section{Conclusion}

The initiation of ART in patients irrespective of CD4 count has been an improvement in the treatment guideline therapy of HIV infected patients.

\section{Acknowledgement}

The present study was a part of Short term studentship project for undergraduate students. The authors are thankful for the support given by the ART center and NACO for sharing the data.

\section{Source of funding}

None.

\section{Conflict of interest}

None.

\section{References}

1. İnci, Ayșe. Evaluation of HIV Infected Elderly Patients. FLORA 2014;19(2):74-9.

2. Reshma SR, Navin AP, Narendranath S. Evaluation of the effects of antiretroviral drug regimen (Stavudine +Lamivudine + Nevirapine) on CD4 count, body weight, and haemoglobin of HIV positive patients: A retrospective study. MJMS 2016;1(2):37-41.

3. Patrikar S. Rate of decline in CD4 count in HIV patients not on antiretroviral therapy. Med J, Armed Forces India 2013;70(2):134-8.

4. R Prasad. Lakhs of HIV deaths can be averted as India follows WHO's recommendations. The Hindu. 2017 May (https://www.thehindu.com/opinion/op-ed/targeted treatment/article18358522.ece?homepage=true - Accessed on 10th January 2019)

5. World Health Organization. Guidelines on when to start antiretroviral therapy and on pre-exposure prophylaxis for HIV. Geneva, Switzerland: World Health Organization; 2015. http://www.who.int/hiv/pub/ guidelines/earlyrelease-arv/en/

6. National AIDS Control Organization. National Strategic Plan for HIV/ AIDS and STI, 2017-2024: paving way for an AIDS free India. New Delhi: Ministry of Health and Family Welfare; 2017. http://naco.gov.in/ sites/default/files/Paving the Way for an AIDS 15122017.pdf

7. Bachani D, Garg R, Rewari BB. Two year treatment outcomes of patients enrolled in india's national first-line antiretroviral therapy programme. Natl Med J India 2010;23(1):7-12.

8. Kumarasamy N, Solomon S, Chaguturu SK. The safety, tolerability and effectiveness of generic antiviral drug regimens for HIV infected patients in south India. AIDS 2003;17:226769. http://dx.doi.org/10.1097/00002030-200310170-00019

9. Pujari S, Dravid A, Gupte N, Joshi K, Bele V. Effectiveness and safety of generic fixed dose combination of tenofovir/ emitricitabine/ efavirenz in HIV 1 infected patients in western India. Medscape J Med 2008;10:196.

10. Sharma A, Wanchu A, Bansal V, Singh S, Varma S. Improvements in CD4 counts in HIV positive patients treated with HAART and antitubercular drugs: An observational study from north India. Indian J Pathol Microbiol 2007;50:905-7.

11. Mrudula ND, Suwarna U P, Khadse R K, Minal P, Shubhangi D K. Statistical Analysis and Evaluation of CD4 Count after 6 Months on ART. Indian J Community Med 2012;37:266-7.

12. Grover G. A Multistate Markov Model Based on CD4 Cell Count for HIV/AIDS Patients on Antiretroviral Therapy (ART): Int J Statist Med Res 2013;2:144-51.

How to cite: Renge PS, Narwane SP, Evaluation of CD4 count in patients receiving ART treatment in a tertiary rural hospital of India. IP Int J Comprehensive Adv Pharmacol 2019;5(1):22-4. 